\title{
The use of bisoprolol in comprehensive treatment of dilated cardiomyopathy in dogs
}

\author{
Elena Kuryatova $^{1}$, Olesya Gruzdova ${ }^{1}$, and Olga Us $^{1,{ }^{*}}$ Aleksey Chubin ${ }^{2}$ \\ ${ }^{1}$ Far Eastern State Agrarian University Blagoveshchensk, 675005, Kuznechnaya Street, 95 , \\ Blagoveshchensk, Russia \\ ${ }^{2}$ Individual entrepreneur Chubin A.N, Veterinary clinic "Elephant", 354008, Vinogradnaya Street, 43 \\ "D", Sochi, Russia
}

\begin{abstract}
Dilated cardiomyopathy is a chronic progressive heart disease leading to the death of the animal. To provide timely and effective medical assistance to dogs suffering from dilated cardiomyopathy, early diagnosis is essential. It allows identifying sick animals before the development of cardiac decompensation and clinical manifestations of congestive heart failure. There are two major diagnostic methods for dilated cardiomyopathy in dogs at the symptomless stage: echocardiography and 24-hour Holter monitoring. If untreated, this pathology progresses over time. For this reason, the clinicians are faced with a challenge of enhancing the quality of an animal's life and prolonging it. Given this, we set the objective of studying the effects of the beta-blocker Bisoprolol (Concor) on myocardial conduction and contractility in dogs with dilated cardiomyopathy and comparing tolerance to this drug taken by dogs in various initial dosages with their therapeutic efficacy. The study object was beta-blocker Bisoprolol (Concor). The experiments were performed on dogs, age 2-5 years, weight $15-30 \mathrm{~kg}$, with dilated cardiomyopathy in the developed chronic Stage C Index B heart failure stage. All dogs underwent comprehensive clinical examinations, tonography, echocardiography, and Holter monitoring. It was established that usage of Bisoprolol (dosage $0.25 \mathrm{mg} / \mathrm{kg}$ ) led to blood pressure decrease, reduced ejection fraction, shortening fraction, and deterioration of the general condition of sick dogs. We have proved therapeutic efficacy and good tolerance of Bisoprolol in the initial dosage of $0.15 \mathrm{mg} / \mathrm{kg}$ taken by dogs every 12 hours.
\end{abstract}

\section{Introduction}

Dilated cardiomyopathy (DCM) is a disease common to many species of mammals. It is characterized by progressive congestive heart failure and cardiac remodeling with ventricles becoming less elliptical and more spherical, dilation of heart chambers dilating and thinning of ventricular walls. The principal causes of this cardiac pathology are toxic, infectious, autoimmune, and metabolic. It can also develop as a result of an endocrine disorder or genetic inheritance (idiopathic cause) $[8,9]$.

\footnotetext{
*Corresponding author: olenka-zhulikova@mail.ru
} 
In the early stages, this pathology is latent due to the operation of compensatory mechanisms. In the decompensated heart failure stage, these mechanisms become overwhelmed and symptoms emerge. As a rule, in $25 \%$ of cases, dogs with DCM suffer a sudden death from paroxysmal ventricular tachycardia. The survival time for sick dogs ranges from 27 to 150 days after discovery of the pathology [8, 13, 22].

Veterinary clinicians are always faced with the challenge of enhancing the quality and prolonging the life of a patient with DCM. Modern DCM drug treatment targets various components of the pathogenesis of the complex syndrome, including ionotropic stimulation of the heart and cardiac unloading. The application of beta-blockers promotes myocardial unloading, as it blocks the activity of catecholamines and modulates diverse neurohormonal relationships, which, in turn, slows down the cascade of pathophysiological reactions in the body $[2,10]$.

The clinical effectiveness of beta-blockers has been studied in a series of trials. There are three most successful programs that are considered fundamental: CIBIS II with Bisoprolol (2,600+ patients with Class 3-4 CHF) showing a 34\% mortality risk reduction $[16,17]$; MERIT-HF with extended-release metoprolol $(4,000+$ patients with Class 3-4 CHF) showing a 34\% mortality risk reduction [19]; COPERNICUS with carvedilol $(2,200+$ with the initial ejection fraction $<25 \%$ ) leading to a $35 \%$ mortality risk reduction (2004) $[12,18]$.

The veterinary cardiology researchers also assessed several options for the practical application of beta-blockers in the treatment of heart diseases in dogs. Despite this, there are no large-scale studies on this topic, including those providing for the determination of therapeutic dosages of these drugs $[6,15]$. In this regard, beta-blocker effects in the canine DCM treatment are of research and practical interest.

The object of this study is the determination of the effects of the beta-blocker Bisoprolol (Concor) on myocardial conduction and contractility in dogs with dilated cardiomyopathy and comparing tolerance to this drug taken by dogs in various initial dosages with their therapeutic efficacy.

\section{Materials and Methods}

The study has been carried out at the following veterinary clinics in Blagoveshchensk, Amur Region: Sole Proprietor Naboka L. A. ("AmurVet") and Sole Proprietor Panyukova T. A. ("VetLife"). The object of the study was the beta-blocker Bisoprolol (Concor) produced by Merck KGaA, Germany.

The experiments were performed on dogs with dilated cardiomyopathy and developed chronic heart failure (Stage C, Index B) [14]. The selected animals predominantly had idiopathic DCM and equivalent characteristics, age 2-5 years, weight $15-30 \mathrm{~kg}$.

They were divided into 3 experimental groups, $5 \mathrm{dogs}$ in each. Normal indicators from the literary source served as control. All experimental groups were on the same treatment regimen (Table 1):

1) Ramipril (Vasotop) - an angiotensin-converting enzyme inhibitor that promotes myocardial remodeling, helps eliminate of myocardial hypoxia, lowers blood pressure, improves vasodilation and kidney perfusion;

2) Pimobendan (Vetmedin) — an ionotropic drug that improves myocardial contractility;

3) a combination of the loop diuretic Furosemide (Lasix) and the potassium-sparing diuretic Spironolactone (Verospiron) that reduce heart preload and eliminate congestions;

4) a low-sodium diet (to reduce fluid retention);

5) oxygen therapy (to eliminate signs of tissue hypoxia) [3, 4]. 
In the first series of experiments, the primary treatment for each experimental group of dogs involved the application of the beta-blocker Bisoprolol (Concor) in different initial dosages compliant with the generally accepted dosage for the study drug - 0.08- 0.25 $\mathrm{mg} / \mathrm{kg}$ every 12 hours [20]. Thus, the first experimental group (O1) received Bisoprolol (Concor) in the dose of $0.08 \mathrm{mg} / \mathrm{kg}$ every 12 hours; the dosage for the second experimental group $(\mathrm{O} 2)$ was $0.15 \mathrm{mg} / \mathrm{kg}$ every 12 hours; the dosage for the third experimental group (O3) was $0.25 \mathrm{mg} / \mathrm{kg}$ every 12 hours. This trial had been performed for 14 days. In the second series of experiments, it was decided to double the dosage of the beta-blocker Bisoprolol (Concor) compared to the initial one. The resulting dosages were as follows: $\mathrm{O} 1-0.15 \mathrm{mg} / \mathrm{kg}$ every 12 hours, $\mathrm{O} 2-0.25 \mathrm{mg} / \mathrm{kg}$ every 12 hours. This trial had lasted for another 14 days. The decision was justified by the need to study the therapeutic effectiveness and tolerability of Bisoprolol (Concor) for dogs following a smooth increase in its dosage. The drugs were administered in the tablet form at home; the effectiveness of the application of the beta-blocker Bisoprolol (Concor) was assessed on days 15 and 30 from the start of the treatment.

Table 1. The treatment regimen for dogs with DCM.

\begin{tabular}{|c|c|}
\hline Groups & Treatment regimen \\
\hline $\mathrm{O} 1$ & $\begin{array}{l}\text { Ramipril (Vasotop), } 0.25 \mathrm{mg} / \mathrm{kg} \text {, ingestion, } 1 \text { time a day. } \\
\text { Pimobendan (Vetmidin), } 0.6 \mathrm{mg} / \mathrm{kg} / \text { day (in two stages, every } 12 \text { hours), } \\
\text { ingestion. } \\
\text { Spironolactone (Verospiron), } 1 \mathrm{mg} / \mathrm{kg} \text {, ingestion, } 2 \text { times a day. } \\
\text { Furosemide (Lasix), } 2 \mathrm{mg} / \mathrm{kg} \text {, ingestion, } 2 \text { times a day. } \\
\text { Bisoprolol (Concor), } 0.08 \mathrm{mg} / \mathrm{kg} \text {, ingestion, } 2 \text { times a day. } \\
\text { Diet (low-sodium) } \\
\text { Oxygen therapy }\end{array}$ \\
\hline $\mathrm{O} 2$ & $\begin{array}{l}\text { Ramipril (Vasotop), } 0.25 \mathrm{mg} / \mathrm{kg} \text {, ingestion, } 1 \text { time a day. } \\
\text { Pimobendan (Vetmidin), } 0.6 \mathrm{mg} / \mathrm{kg} / \text { day (in two stages, every } 12 \text { hours), } \\
\text { ingestion. } \\
\text { Spironolactone (Verospiron), } 1 \mathrm{mg} / \mathrm{kg} \text {, ingestion, } 2 \text { times a day. } \\
\text { Furosemide (Lasix), } 2 \mathrm{mg} / \mathrm{kg} \text {, ingestion, } 2 \text { times a day. } \\
\text { Bisoprolol (Concor), } 0.15 \mathrm{mg} / \mathrm{kg} \text {, ingestion, } 2 \text { times a day. } \\
\text { Diet (low-sodium) } \\
\text { Oxygen therapy }\end{array}$ \\
\hline $\mathrm{O} 3$ & $\begin{array}{l}\text { Ramipril (Vasotop), } 0.25 \mathrm{mg} / \mathrm{kg} \text {, ingestion, } 1 \text { time a day. } \\
\text { Pimobendan (Vetmidin), } 0.6 \mathrm{mg} / \mathrm{kg} / \text { day (in two stages, every } 12 \text { hours), } \\
\text { ingestion. } \\
\text { Spironolactone (Verospiron), } 1 \mathrm{mg} / \mathrm{kg} \text {, ingestion, } 2 \text { times a day. } \\
\text { Furosemide (Lasix), } 2 \mathrm{mg} / \mathrm{kg} \text {, ingestion, } 2 \text { times a day. } \\
\text { Bisoprolol (Concor), } 0.25 \mathrm{mg} / \mathrm{kg} \text {, ingestion, } 2 \text { times a day. } \\
\text { Diet (low-sodium) } \\
\text { Oxygen therapy }\end{array}$ \\
\hline
\end{tabular}

The clinical examination of sick animals was carried out according to the generally accepted methodology. The results were recorded in the appropriate protocols and case reports. The established procedure for the examination was as follows: visual inspection and palpation of the region of the cardiac beat and pulse, auscultation of the heart and lungs, measuring of heart rate and respiratory movements per minute. During the examination, the color and state of the skin and mucous membranes were noted $[5,7]$.

Blood pressure was measured with a veterinary tonometer "Pettrust". The researchers put a cuff of the appropriate size on the animal's paw and connected it to the tonometer. After pumping of air into the cuff and its subsequent bleeding, the measurement results 
appeared on the display. The measurements were performed 6-8 times with a 1015 minutes interval. After that, the average value was calculated [21].

The heart contractility in dogs with DCM was studied with the ultrasonography device "Mindray DC N6". For this, the dogs were held in the supine position without the use of sedatives and general anesthesia [1]. The 24-hour ECG monitoring was performed using the veterinary Holter device "Vet-scoutdextronix". The electrodes were attached according to the instructions and generally accepted methods [11]. To fix the electrodes in place and protect the Holter device, the researchers put custom-made tight clothing onto the dog's body (see Figure). The ECG data had been recorded for 24 hours.

\section{Results of the Study}

The primary clinical examination of dogs with DCM revealed the following symptoms: pallor of the mucous membranes, capillary refill time $>3 \mathrm{sec}$, rapid breathing, and lethargy. The body temperature and blood pressure were within the physiological standard (Table 2). Dogs in all study groups had tachyarrhythmia. In Group O1, this indicator deviated from the standard by $7.5 \%$, in Group $\mathrm{O} 2$ - by $10.25 \%$, in Group $\mathrm{O} 3$ - by $6.1 \%$.

Table 2. Physiological parameters of dogs before the treatment, $M \pm m, n=5$.

\begin{tabular}{|c|c|c|c|c|}
\hline Indicators & $\begin{array}{c}\text { Standard per } \\
\text { R. S. Karmaliev, } \\
2005\end{array}$ & O1 & $\mathrm{O} 2$ & $\mathrm{O} 3$ \\
\hline Body temperature & $37.5-39.0$ & $38.6 \pm 0.13$ & $38.0 \pm 0.15$ & $38.4 \pm 0.11$ \\
\hline $\begin{array}{l}\text { HR (during examination) } \\
\text { / } \min \end{array}$ & $70-120$ & $129.0 \pm 2.11$ & $132.3 \pm 1.05$ & $127.3 \pm 1.89$ \\
\hline $\begin{array}{l}\text { HR (at rest, during sleep) } \\
\text { / min }\end{array}$ & $70-120$ & $115.7 \pm 2.94$ & $100.0 \pm 5.46$ & $114.7 \pm 2.73$ \\
\hline $\mathrm{BP}(\mathrm{mmHg})$ & $100-140$ & $116.0 \pm 2.32$ & $110.7 \pm 3.36$ & $119.0 \pm 2.73$ \\
\hline
\end{tabular}

During the primary echocardiography (EchoCG) of dogs with DCMP, in addition to changes in the anatomical dimensions of the cavities and the thickness of the heart walls, changes in the ejection fraction (EF) and shortening fraction (SF) were also recorded. The researchers quantified the supraventricular tachyarrhythmias (SVT) and ventricular tachyarrhythmias (VT) in the ECG data recorded during the 24-hour Holter monitoring. The obtained primary data are listed in Table 3. Thus, according to the EchoCG indicators of the dogs, compared to the standard, in Group O1, the ejection fraction was reduced by $24.4 \%$, in Group $\mathrm{O} 2$ - by $18.2 \%$, in Group O3 - by $25.7 \%$. The shortening fraction was also decreased compared to the standard: in Group O1 - by $13.3 \%$, in Group $\mathrm{O} 2$ - by $6.7 \%$, in Group O3 - by $16.7 \%$

The results of the Holter ECG monitoring revealed the following count of SVT occurrences over 24 hours: 64.3 in Group O1, 75.3 in Group O2, 71.3 in Group O3. The VT occurrences in the 24-hour ECG data were registered as follows: 121.3 in Group O1, 122.7 in Group O2, 122.7 in Group O3.

In the first series of experiments, all dogs had received standard supporting therapy with the beta-blocker Bisoprolol (Concor) in various initial doses (Table 1) for 14 days. After that, the animals underwent a follow-up examination. The changes in the physiological parameters of dogs in the experimental groups are listed in Table 4. 
Table 3. Study of cardiac conduction (by Holter monitoring) and cardiac contractility (by EchoCG) in dogs with DCM before the treatment, $M \pm m, n=5$.

\begin{tabular}{|c|c|c|c|c|}
\hline Indicators & $\begin{array}{c}\text { Standard (per } \\
\text { Morrison et } \\
\text { al., 1992) }\end{array}$ & O1 & O2 & O3 \\
\hline $\begin{array}{c}\text { Ejection fraction (EF), } \\
\%\end{array}$ & $0.66-0.87$ & $0.5 \pm 0.01$ & $0.54 \pm 0.017$ & $0.49 \pm 0.021$ \\
\hline $\begin{array}{c}\text { Shortening fraction } \\
\text { (SF), \% }\end{array}$ & $0.30-0.49$ & $0.26 \pm 0.015$ & $0.28 \pm 0.023$ & $0.25 \pm 0.019$ \\
\hline \multicolumn{5}{|c|}{ ECG per H0olter monitoring } \\
\hline SVT per day & 0 & $64.3 \pm 1.89$ & $75.3 \pm 1.26$ & $71.3 \pm 1.68$ \\
\hline VT per day & 0 & $121.3 \pm 2.52$ & $127.0 \pm 2.34$ & $122.7 \pm 2.31$ \\
\hline
\end{tabular}

Table 4. Physiological parameters of dogs on Day 14 of the treatment, $M \pm m, n=5$.

\begin{tabular}{|c|c|c|c|c|}
\hline Indicators & $\begin{array}{c}\text { Standard per } \\
\text { R. S. Karmaliev, } \\
2005\end{array}$ & O1 & O2 & O3 \\
\hline Body temperature & $37.5-39.0$ & $38.2 \pm 0.25$ & $38.8 \pm 0.21$ & $38.6 \pm 0.17$ \\
\hline $\begin{array}{c}\text { HR (during } \\
\text { examination) / min }\end{array}$ & $70-120$ & $125.7 \pm 2.52$ & $128.0 \pm 2.34$ & $117.0 \pm 2.96$ \\
\hline $\begin{array}{c}\text { HR (at rest, during } \\
\text { sleep) / min }\end{array}$ & $70-120$ & $107.7 \pm 3.57$ & $116.0 \pm 2.92$ & $95.7 \pm 2.04$ \\
\hline BP (mmHg) & $100-140$ & $113.3 \pm 2.52$ & $105.3 \pm 3.15$ & $95.0 \pm 2.53$ \\
\hline
\end{tabular}

After 14 days from the start of the treatment, the clinical examination of dogs of Groups $\mathrm{O} 1$ and $\mathrm{O} 2$ revealed an increase in CRT up to 3 seconds. The visible mucous membranes (VMM) were pale pink, rapid breathing (stress reaction) and rapid heartbeat were also observed. The heart rate of dogs in Group O1 was increased by $4.75 \%$, in Group O3 — by $6.7 \%$ (compared to the standard). Against the primary examination data, it was possible to trace the positive trend - the reduction in the heart rate, and therefore the cupping of tachyarrhythmia. The dogs in Group O3 had pallor mucous membranes, heavy breathing, and lethargy symptoms. The heart rate was within the physiological standard, the blood pressure was decreased by 5\% (compared to the standard). The owners of dogs of Groups $\mathrm{O} 1$ and $\mathrm{O} 2$ noted good tolerability of the drugs and an increase in activity/appetite. In contrast, the owners of the dogs of Group 3 noted a depressed state, lethargy, food refusal, and periodic vomiting.

Table 5. Study of cardiac conduction (by Holter monitoring) and cardiac contractility (by EchoCG) in dogs with DCM on Day 14 of the treatment, $\mathrm{M} \pm \mathrm{m}, \mathrm{n}=5$.

\begin{tabular}{|c|c|c|c|c|}
\hline Indicators & $\begin{array}{c}\text { Standard (per } \\
\text { Morrison et } \\
\text { al., 1992) }\end{array}$ & O1 & O2 & O3 \\
\hline $\begin{array}{c}\text { Ejection fraction } \\
\text { (EF), } \%\end{array}$ & $0.66-0.87$ & $0.57 \pm 0.063$ & $0.64 \pm 0.015$ & $0.45 \pm 0.017$ \\
\hline $\begin{array}{c}\text { Shortening } \\
\text { fraction (SF), } \%\end{array}$ & $0.30-0.49$ & $0.28 \pm 0.025$ & $0.32 \pm 0.019$ & $0.23 \pm 0.015$ \\
\hline \multicolumn{5}{|c|}{ ECG per Holter monitoring } \\
\hline SVT per day & 0 & $44.3 \pm 3.15$ & $54.7 \pm 2.73$ & $47.7 \pm 2.52$ \\
\hline VT per day & 0 & $86.3 \pm 1.47$ & $98.0 \pm 2.54$ & $105.0 \pm 2.73$ \\
\hline
\end{tabular}


According to the results of cardiological screening (Table 5), compared to the primary examination data, there is a notable increase in the indicators of ejection and shortening fractions in Groups $\mathrm{O} 1$ and $\mathrm{O} 2$. Compared to the standard, these indicators remain decreased; in Group O1, the EF is reduced by $13.6 \%$ and the SF — by $6.7 \%$. In Group O2, the $\mathrm{EF}$ is $3 \%$ lower than the standard, and the SF is within the physiological standard. In contrast, in Group O3, a negative trend was observed: the EF and SF were even lower than during the primary examination. Compared to the standard, the EF was reduced by $31.8 \%$, the SF - by $23.3 \%$.

The 24-hour ECG records (obtained by Holter monitoring) revealed a positive trend in all experimental groups of dogs, compared to the primary examination data. For instance, the SVT count in Group O1 reduced by $31.1 \%$, in Group O2 - by $27.3 \%$, in Group O3 by $33.1 \%$. The VT count in Group O1 reduced by $28.8 \%$, in Group $\mathrm{O} 2$ - by $22.8 \%$, in Group O3 - by $14.4 \%$.

At the end of the first series of experiments, it was decided to dechallenge Bisoprolol (Concor) gradually for dogs in Group O3 due to the poor tolerability of the drug in the initial dose of $0.25 \mathrm{mg} / \mathrm{kg}$ which was characterized by a decrease in blood pressure, deterioration of the wellbeing of the animals and a greater decrease in EF/SF. Group O3 didn't take part in further study.

In the first series of experiments, it was decided to double the dosage of the beta-blocker Bisoprolol (Concor) for Groups O1 and O2. Consequently, for the next 14 days, the dogs in Group O1 received Bisoprolol (Concor) in a dose of $0.15 \mathrm{mg} / \mathrm{kg}$ every 12 hours. The dosage for dogs in Group $\mathrm{O} 2$ was $0.25 \mathrm{mg} / \mathrm{kg}$ every 12 hours. The changes in the physiological parameters of dogs in the experimental groups are listed in Table 6.

Table 6. Physiological parameters of dogs on Day 28 of the treatment, $\mathrm{M} \pm \mathrm{m}, \mathrm{n}=5$.

\begin{tabular}{|c|c|c|c|}
\hline Indicators & $\begin{array}{c}\text { Standard per } \\
\text { R. S. Karmaliev, 2005 }\end{array}$ & $\mathrm{O} 1$ & $\mathrm{O} 2$ \\
\hline Body temperature & $37.5-39.0$ & $38.4 \pm 0.23$ & $38.6 \pm 0.17$ \\
\hline $\begin{array}{c}\text { HR (during examination) / } \\
\text { min }\end{array}$ & $70-120$ & $120.0 \pm 2.11$ & $114.3 \pm 1.26$ \\
\hline $\begin{array}{c}\text { HR (at rest, during sleep) / } \\
\text { min }\end{array}$ & $70-120$ & $105.0 \pm 1.76$ & $96.7 \pm 2.31$ \\
\hline BP (mmHg) & $100-140$ & $114.7 \pm 2.31$ & $101.0 \pm 3.63$ \\
\hline
\end{tabular}

On Day 28 of the experiment, all dogs under the study had the following signs: pale pink VMM, CRT of 3-5 seconds, rapid rhythmic breathing, heart rate within the physiological standard, blood pressure at the lower limit of the physiological standard. The owners of the dogs of both groups noted good tolerability of the drugs, preservation of appetite, and absence of the gastrointestinal tract disorders. In the second experimental group $(\mathrm{O} 2)$, a slight decrease in activity was observed.

The analysis of data in Table 7 reveals that in the first experimental group (O1), the studied EchoCG parameters of the ejection and shortening fractions were within the physiological standard, which indicates an improvement in myocardial contractile function in dogs with DCM. In the second experimental group $(\mathrm{O} 2)$, compared to the previous study, the ejection fraction was reduced by $7.6 \%$ (against the standard). The shortening fraction in Group $\mathrm{O} 2$ was at the lower limit of the standard.

The data from the 24-hour EGG (Holter) monitoring also revealed a positive trend - a decrease in the SVT and VT count in both experimental groups of dogs. In particular, compared to the previous study, in Group O1, the SVT count decreased by $16.5 \%$, the VT count - by $25 \%$. In Group O2, the SVT count decreased by $176.2 \%$, the VT count — by $25.2 \%$ (Table 5). 
Table 7. Study of cardiac conduction (by Holter monitoring) and cardiac contractility (by EchoCG) in dogs with DCM on Day 28 of the treatment, $\mathrm{M} \pm \mathrm{m}, \mathrm{n}=5$.

\begin{tabular}{|c|c|c|c|}
\hline Indicators & $\begin{array}{l}\text { Standard (per } \\
\text { Morrison et } \\
\text { al., 1992) }\end{array}$ & $\mathrm{O} 1$ & $\mathrm{O} 2$ \\
\hline Ejection fraction (EF), \% & $0.66-0.87$ & $0.68 \pm 0.023$ & $0.61 \pm 0.013$ \\
\hline Shortening fraction (SF), \% & $0.30-0.49$ & $0.36 \pm 0.019$ & $0.31 \pm 0.015$ \\
\hline \multicolumn{4}{|c|}{ ECG per Holter monitoring } \\
\hline SVT per day & 0 & $37.0 \pm 2.73$ & $45.3 \pm 2.52$ \\
\hline VT per day & 0 & $64.7 \pm 1.47$ & $73.3 \pm 2.31$ \\
\hline
\end{tabular}

\section{Discussion}

The modern cardiological practice relies on the use of beta-blockers. This class of drugs has great potential. They are applicable in many clinical situations. A practitioner should not be misled by disagreements between the authors of various studies of the efficiency of administering beta-blockers to animals with CHF and recent critical reviews of individual trials. These studies sometimes feature different types and brands of beta-blockers (selective and non-selective), and every cardiologist should pay attention to this fact.

According to the results of our study, Bisoprolol administered in an initial dose of $0.08-$ $0.15 \mathrm{mg} / \mathrm{kg}$ has a cardioprotective effect. The best results were achieved with the use of Bisoprolol in a dose of $0.15 \mathrm{mg} / \mathrm{kg}$ : it significantly reduced the count of rhythm disturbances (SVT, VT), improved myocardial contractility (EF, SF), reduced heart rate. The drug has a weak hypotensive effect and does not cause prominent hypotension.

At the same time, it must be noted that the application of Bisoprolol in a dose of $0.08 \mathrm{mg} / \mathrm{kg}$ is not particularly effective. Therefore, for continuous therapy, a further increase in the dosage of the drug and regular monitoring of cardiac activity is required. An experimental increase in the dosage of Bisoprolol up to $0.15 \mathrm{mg} / \mathrm{kg}$ after 14 days of treatment of dogs of one experimental group resulted in a positive trend compared to the results achieved with the initial dosage of $0.08 \mathrm{mg} / \mathrm{kg}$.

The administration of Bisoprolol (Concor) in a dose of $0.08 \mathrm{mg} / \mathrm{kg}$ is advisable for dogs with DCM and the initially diagnosed hypotension because the study has proved that such a minimal effective dose has the smallest hypotensive effect. It should also be noted that this dose of beta-blocker can, in theory, be administered to dogs with chronic heart failure in the decompensation stage (Stage D, according to the international classification of chronic heart failure), but to provide precise recommendations, further studies on this topic are required.

The use of Bisoprolol in the initial maximum allowable dosage of $0.25 \mathrm{mg} / \mathrm{kg}$ led to a strong hypotensive effect in dogs of the experimental group, evident in weakness, lethargy, unsteady gait, and food refusal. The researchers also registered the development of bradycardia and the deterioration of the myocardial contractile function (an even greater decrease in the EF/SF).

At the same time, a gradual increase in the Bisoprolol dosage to $0.25 \mathrm{mg} / \mathrm{kg}$ after 14 days of use in a dose of $0.15 \mathrm{mg} / \mathrm{kg}$ in the second experimental group resulted in good tolerability of the drug. The hypotensive effect and bradycardia were also noted, but they were less pronounced than in dogs taking Bisoprolol in an initial dose of $0.25 \mathrm{mg} / \mathrm{kg}$. The development of hypotension and bradycardia can be related to the simultaneous use of Ramipril (Vasotop), an ACE inhibitor that also has a hypotensive effect due to vasodilation. In addition to this, a gradual increase in the Bisoprolol dosage to $0.25 \mathrm{mg} / \mathrm{kg}$ resulted in the 
reduction of the EF/SF indicators which indicates a deterioration of the myocardial contractile function.

\section{Conclusions}

1. We have proved therapeutic efficacy, good tolerance and cardioprotective effect of Bisoprolol (Concor) administered in a dose of $0.15 \mathrm{mg} / \mathrm{kg}$, both for the initial dosage and with its gradual increase.

2. The application of Bisoprolol (Concor) in the maximum allowed dose is not advisable for dogs with DCM since this method causes deterioration in the myocardial contractility, and, consequently, in the cardiac output, which inevitably aggravates the CHF.

3. The data obtained during the study can be applied to the treatment of DCM in dogs (Stage C, Index B), as well as cited during lectures and practical sessions for students of veterinary schools (for the Cardiology discipline).

The authors of this publication would like to express their deep appreciation and gratitude to Lyudmila Anatolyevna Naboka, Head of the Amurvet clinic, Candidate of Biological Science, and Tatyana Aleksandrovna Panyukova, Head of the VetLife clinic. Thank you for your attention, assistance and support at various stages of the research work.

\section{Reference}

1. O. Yu. Atkov Ultrasonic Cardiography, 456 (2019).

2. T. V. Bardyukova The Role of Sympathoadrenal System in the Pathogenesis of Chronic Heart Failure in Dogs, 4-6 (2002)

3. Yu. N. Belenkov The Principles of Rational Treatment of Heart Failure 74 (2000)

4. V. E. Wingfield Secrets of Emergency Veterinary Care, 608 (2000)

5. V. S. Gerke Basics of Cardiological Examination of Dogs. VetPharma. 4 (15), 40-46 (2013)

6. V. S. Gerke, Beta-Blockers. Application in Veterinary, 6 (22), 38-42 (2014)

7. V. S. Gerke Cardiological Screening in General Veterinary Practice, 3 (37), 97-100. (2017)

8. V Gerhard. Asymptomatic Dilated Cardiomyopathy in Dogs: Latent Stage of the Disease, Invisible to the Owner, 3, 14-17. (2016)

9. F. G. Gizatullina Heart Diseases in Dogs (Diagnostics, Treatment, and Prevention) 144 (2002)

10. M. A. Gurevich Beta-Adrenergic Blocking Agents in Heart Failure, Therapy Journal of Cardiology, 1, 77-86 (2009)

11. G. Dabinok. Electrocardiography in Dog. Cardiomyopathies and Indications for the Application of Electrocardiographic (ECG) Studies, 3, 16-19. (2000)

12. V. K. Illarionova Beta-Adrenergic Blocking Agents in Chronic Heart Failure Treatment of Dogs, Journal of Veterinary. Small Domestic and Wild Animals, 1, 4143. (2010)

13. B. U. Kin Cardiorespiratory Diseases, 796-922 (2005)

14. A. G. Komolov. Chronic Heart Failure Classification. Proceedings of the 10th Moscow International Veterinary Congress, 5-6. (2002) 
15. S. N. Tereshchenko. Beta-Adrenergic Blocking Agents: Options of Expansion of the Indications for Use. Consilium Medicum, 5 (T7), 22-30. (2005)

16. CIBIS investigators and committees. A randomized trial of betablockade in heart failure. The cardiac insufficiency Bisoprolol study (CIBIS) Circulation, 90, 1765-1773 (1994)

17. CIBIS, II investigators and committees. The cardiac insufficiency bisoprolol Study II (CIBIS II) Lancet, 353, 9-13. (1999)

18. W. H. Frishman. Beta-adrenergic blockers: a 50-year historical perspective, American Journal of Therapeutics, 15(6), 565-576 (2008)

19. MERIT, HF study group. Effect of metoprolol $\mathrm{CR} / \mathrm{XL}$ in chronic heart failure. Metoprolol CR/XL randomized intervention trial in congestive heart failure (MERITHF) Lancet, 353, 2001-2007, (1999)

20. R. Proietti, V. Russo, A. AlTurki Anti-arrhythmic therapy in patients with nonischemic cardiomyopathy, Pharmacol Res, 4, 27-32, (2019)

21. H. M. Stephenson Screening for dilated cardiomyopathy in GreatDanes in the United Kingdom, $J$ Vet Intern Med, 5, 1140-1147 (2012)

22. C. Vollmar, A. Vollmar, B.W. Keene Dilated cardiomyopathy in 151 Irish Wolfhounds: Characteristic clinical findings, life expectancy and causes of death, 245, 15-21 (2019) 